\title{
Powder X-ray characterization of djenkolic acid
}

Petr Melnikova)

CCET-UFMS, 79070-900 Cidade Universitária, s/n, Campo Grande, MS, Brazil

Alexandre Cuin, ${ }^{\text {b) }}$ Pedro P. Corbi, ${ }^{\text {c) }}$ Maurício Cavicchioli, ${ }^{\text {d) }}$ and Antonio C. Massabni ${ }^{\text {e) }}$

Department of General and Inorganic Chemistry, Institute of Chemistry-UNESP, P.O. Box 355,

14800-970 Francisco Degni, s/n, Araraquara, SP, Brazil

(Received 7 August 2000; accepted 4 November 2000)

$\mathrm{X}$-ray powder diffraction data for the orthorhombic natural amino acid djenkolic acid, $\mathrm{C}_{7} \mathrm{H}_{14} \mathrm{~N}_{2} \mathrm{O}_{4} \mathrm{~S}_{2}$, is described in this paper. The orthorhombic cell parameters are: $a=8.12 \AA, b$ $=12.16 \AA$, and $c=5.38 \AA$. (C) 2001 International Centre for Diffraction Data.

Key words: powder diffraction, djenkolic acid, amino acids

\section{INTRODUCTION}

Djenkolic acid $\left(\mathrm{C}_{7} \mathrm{H}_{14} \mathrm{~N}_{2} \mathrm{O}_{4} \mathrm{~S}_{2}-S, S^{\prime}\right.$-methylenebiscysteine, Figure 1) is an amino acid of vegetal origin which is contained in the seeds of Acacia species and in djenkol beans (Pithecolobium lobatum). Besides the two pairs of carboxylic and amino groups, it also contains two sulfur atoms connecting the methylene groups in a way similar to that of thioeters, but different from a typical sulfur present in other natural amino acids.

A recent reference (Dictionary of Natural Products, 1997) mentions the structure determination of djenkolic acid as an accomplished fact. However, closer examination surprisingly shows that the crystal structure has actually been determined only for its derivative (Bigoli et al., 1982), $S, S^{\prime}$-methylenebiscysteine monohydrochloride. The only data available on djenkolic acid itself is a private communication by Eli Lilly \& Co reporting a set of relative intensities $\left(I / I_{0}\right)$ and interplanar distances $(d)$ for a sample of unknown origin and characteristics (Powder Diffraction File, 1994).

Djenkolic acid is known to possess a net biological activity, but its effects are quite unpredictable, varying from nervous reactions to serious toxic complications and even anaphylaxy (Jarusiripipat $e t$ al., 1988). It seems rather peculiar that a substance which is part of nutrients and has the ability to trap free radicals might be so toxic. Pharmacologically speaking, we may be dealing with a system with another component that is responsible for "switching on or off" the cited reactions and consequent clinical manifestations. Several well-known examples are calcium ions and blood coagulation system factors; potassium and digitalic alkaloids; and so forth.<smiles>NC(CSCSCC(N)(I)C(=O)O)C(=O)O</smiles>

Figure 1. Schematic representation of djenkolic acid.
The aim of the present work is to elaborate on an appropriate synthetic method and to characterize djenkolic acid using the $\mathrm{X}$-ray powder diffraction technique.

\section{EXPERIMENTAL}

Synthesis Djenkolic acid was prepared according to a published method (Armstrong and Vigneaud, 1947). Some modifications were introduced in order to avoid the recrystallization step, since the compound, after being formed, showed the tendency to decompose when performing these operations.

\section{RESULTS}

Elemental analysis for $\mathrm{C}, \mathrm{H}, \mathrm{N}$, and $\mathrm{S}$ was carried out using CHNS-O EA 1110 Analyzer, CE Instruments. The experimental data reported in Table I fit well to the empirical formula $\mathrm{C}_{7} \mathrm{H}_{14} \mathrm{~N}_{2} \mathrm{O}_{4} \mathrm{~S}_{2}$.

The $\mathrm{X}$-ray diffraction pattern was recorded using a $\mathrm{Si}$ emens D-5000 Kristalloflex diffractometer with a $\mathrm{Ni}$ filter and $\mathrm{Cu} K \alpha$ radiation. Germanium was used as an internal standard. Comparison of the observed X-ray pattern shown in Figure 2 with JCPDS Database files showed that $I / I_{0}$ and $d$ parameters of the compound are identical to an early reported sample (Powder Diffraction File, 1994). Indexing the $\mathrm{X}$-ray data was carried out considering their striking resemblance to an orthorhombic polymorph modification of another natural amino acid (L-cysteine) (Kerr and Ashmore, 1973). This similarity suggested the initial values of the lattice parameters, which were refined by a least-squares refinement and are given in Table II, along with the values for $L$-cysteine. The experimental data for the diffraction pattern and the assigned indexing are reported in Table III.

TABLE I. Analytical results for djenkolic acid.

\begin{tabular}{ccc}
\hline Elements & Calc. (wt \%) & Found (wt \%) \\
\hline $\mathrm{C}$ & 33.06 & 32.51 \\
$\mathrm{H}$ & 5.55 & 5.25 \\
$\mathrm{~N}$ & 25.21 & 25.61 \\
$\mathrm{~S}$ & 11.02 & 10.58 \\
\hline
\end{tabular}

\footnotetext{
${ }^{a)}$ Electronic mail: petrmelnikov@yahoo.com

b) Electronic mail: alexcuin@iq.unesp.br

c) Electronic mail: pedrocorbi@yahoo.com

${ }^{d)}$ Electronic mail: maurca $\backslash \mathrm{i} @$ iq.unesp.br

e) Electronic mail: massabni@iq.unesp.br
} 


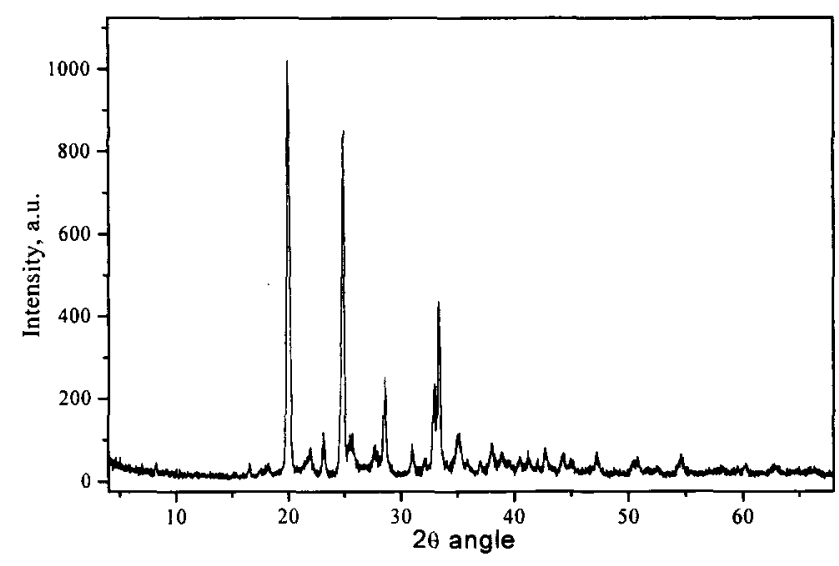

Figure 2. X-ray diffractogram of synthesized djenkolic acid.
TABLE II. Comparison of lattice parameters of djenkolic acid and $L$-cysteine.

\begin{tabular}{lccc}
\hline \hline Compound & $a(\AA)$ & $b(\AA)$ & $c(\AA)$ \\
\hline Djenkolic acid & 8.12 & 12.16 & 5.38 \\
$L$-cysteine & 8.12 & 12.19 & 5.43 \\
\hline
\end{tabular}

\section{v. CONCLUSIONS}

The crystal structure of djenkolic acid can be considered to be an asymmetric derivative of $L$-cysteine and autoblocked against common reagents. It may be the cause of its low reactivity and solubility.

TABLE III. Powder X-ray diffraction data for the $\mathrm{C}_{7} \mathrm{H}_{14} \mathrm{~N}_{2} \mathrm{O}_{4} \mathrm{~S}_{2}$ sample.

\begin{tabular}{|c|c|c|c|c|c|c|c|}
\hline$I / I_{0}$ & $h k l$ & $d_{\mathrm{obs}} \AA$ & $d_{\text {calc }} \AA$ & $I / I_{0}$ & $\overline{h k l}$ & $d_{\text {obs }}(\AA)$ & $d_{\text {calc }}(\AA)$ \\
\hline 5 & 110 & 6.75 & 6.753 & 7 & 050 & 2.432 & 2.432 \\
\hline 5 & 020 & 6.08 & 6.079 & 5 & 311 & 2.371 & 2.371 \\
\hline 40 & 101 & 4.45 & 4.485 & 5 & 222 & 2.116 & 2.116 \\
\hline 5 & 200 & 4.06 & 4.060 & 5 & 400 & 2.030 & 2.030 \\
\hline 7 & 210 & 3.85 & 3.851 & 7 & 142 & 1.965 & 1.955 \\
\hline 100 & 130 & 3.58 & 3.626 & 5 & 161 & 1.847 & 1.847 \\
\hline 6 & 201 & 3.25 & 3.241 & 5 & 013 & 1.790 & 1.774 \\
\hline 5 & 211 & 3.14 & 3.131 & 5 & 152 & 1.768 & 1.761 \\
\hline 5 & 040 & 3.04 & 3.040 & 5 & 440 & 1.682 & 1.688 \\
\hline 5 & 230 & 2.868 & 2.868 & 3 & 213 & 1.638 & 1.626 \\
\hline 6 & 221 & 2.867 & 2.860 & 3 & 441 & 1.612 & 1.611 \\
\hline 9 & 140 & 2.847 & 2.847 & 3 & 270 & 1.597 & 1.597 \\
\hline 40 & 002 & 2.686 & 2.690 & 3 & 233 & 1.531 & 1.521 \\
\hline 7 & 041 & 2.652 & 2.645 & 3 & 451 & 1.498 & 1.497 \\
\hline 5 & 102 & 2.575 & 2.554 & & & & \\
\hline
\end{tabular}

\section{DISCUSSION}

The structural similarity of djenkolic acid with $L$-cysteine mentioned before may be due to the fact that the zwitterion acts as the periodic repeat unit not only in an amino acid network, but also in the network of its derivatives. Thus, in djenkolic acid monohydrochloride, two parts of the coupled zwitterion that should be chemically nonequivalent, appear to be structurally equivalent.

As deduced from electron density measurements, the protons in $S, S^{\prime}$-methylenebiscysteine monohydrochloride are distributed in a disordered manner between carbonyl groups. So, the whole arrangement would resemble a compact infinite sequence of $L$-cysteine units (Armstrong and Vigneaud, 1947). By contrast, in djenkolic acid, which cannot possess a spare monovalent cation (proton or alkaline metal), polar groups become autoblocked and it may be the reason for its extremely low solubility in water. It may also cause the poor reactivity of djenkolic acid since its functional groups would be inaccessable for common reagents.

\section{ACKNOWLEDGMENTS}

The authors are indebted to FAPESP and CNPq (Brazilian Agencies) for financial support.

Armstrong, M. D., and Vigneaud, V. (1947). " A new synthesis of djenkolic acid," J. Biol. Chem. 168, 373-377.

Bigoli, F., Lanfranchi, M., Leporati, E., Nardeli, M., and Pellinghelli, M. A. (1982). "The structure of $S, S^{\prime}$-methylenebis $(L$-cysteine) monohydrochloride," Acta Crystallogr., Sect. B: Struct. Crystallogr. Cryst. Chem. B38, 498-502.

Dictionary of Natural Products (1997). CD-ROM Database, Version 6 (Chapman \& Hall, London).

Eli Lilly \& Co. (private communication).

Jarusiripipat, C., Shapiro, J. I., and Chan, L. (1988). "Djenkolic acid induces acute renal failure," Kidney Int. 33, 359-359.

Kerr, K. A., and Ashmore, J. P. (1973). "Structure and conformation of orthorhombic L-cysteine," Acta Crystallogr., Sect. B: Struct. Crystallogr. Cryst. Chem. B29, 2124-2127.

Powder Diffraction File Database (1994). 08-0660 (JCPDS-ICDD). 